\title{
Хроническая обструктивная болезнь легких у жителей крупного промышленного центра: эпидемиология и факторы риска
}

ГОУ ВПО "Самарский государственный медицинский университет": 443099, Самара, ул. Чапаевская, 89

\section{A.V.Zhestkov, V.V.Kosarev, S.A.Babanov \\ Chronic obstructive pulmonary disease among residents of a large industrial city: epidemiology and risk factors}

\begin{abstract}
Summary
The authors have analyzed epidemiology of COPD at a large industrial city of the Middle Volga region. Two thousand and sixty three persons (903 men and 1,160 women) of four age groups (30-39 years, 40-49 years, 50-59 years, $\geq 60$ years) were examined in Kirovsky and Krasnoglisky districts of Samara. COPD was detected in $14.49 \%$ of the participants $(10.76,10.89,15.88$ and $21.30 \%$ in the age groups, respectively), in $18.72 \%$ of the men and in $11.21 \%$ of the women. The established leading risk factors of COPD were male gender, age, smoking history, ecology hazards, genetic predisposition, education level, marriage status.

Key words: epidemiology, chronic obstructive pulmonary disease.
\end{abstract}

\section{Резюме}

На эпидемиологическом этапе были обследованы 2063 человека (903 мужчины и 1160 женщин) 4 возрастных групп (30-39, 40-49, $50-59, \geq 60$ лет) в Кировском и Красноглинском районах города Самары. Результаты исследования показали достаточно высокую распространенность хронической обструктивной болезни легких (ХОБЛ) в крупном промышленном центре Среднего Поволжья. В общей выборке ХОБЛ была выявлена у 14,49\% от 2063 обследованных независимо от пола (30-39 лет - 10,76 \%, 40-49 лет - 10,89 \%, 50-59 лет $-15,88 \%, 60$ лет и старше - 21,30\%). Среди мужчин ХОБЛ диагностирована в $18,72 \%$ случаев (от 903 обследованных), среди женшин (1 160 обследованных) - в 11,21\% ( $p<0,001)$. Доказано, что ведушими факторами риска развития ХОБЛ являются мужской пол, возраст, табакокурение, экологические условия, наследственность, уровень образования, семейный статус.

Ключевые слова: эпидемиология, хроническая обструктивная болезнь легких.

В Российской Федерации среди заболеваний органов дыхания хроническая обструктивная болезнь легких (ХОБЛ) является наиболее распространенной (> $55 \%$ случаев) [1]. Это одна из важнейших проблем здравоохранения. ХОБЛ становится причиной роста временной нетрудоспособности, инвалидности и преждевременной смертности [2]. Прогноз специалистов остается неблагоприятным: ожидается, что к 2020 г. ХОБЛ займет 3-е место среди причин смертности в мире [2-4]. Эксперты Всемирного банка предполагают также глобальное увеличение экономического ущерба от этого заболевания в последующие 20 лет.

В последнее 10-летие ХОБЛ была выделена в особую нозологическую форму, имеющую соответствующую стадийность, а также сформированы новые подходы к трактовке заболевания, методам его диагностики и профилактики [2, 3]. В то же время существовавшая длительное время неоднородность мнений в определении и методах постановки диагноза ХОБЛ, отсутствие четкой классификации не способствовали своевременному выявлению данной патологии, что привело к практически полному отсутствию достоверных сведений о фактической распространенности, факторах риска заболевания и региональных особенностях $[5,6]$. Изучения частоты ХОБЛ особенно актуально в связи с ухудшени- ем экологической обстановки, широкой распространенностью табакокурения, влиянием профессиональных вредностей, поздней диагностикой бронхообструктивного синдрома [4-7].

Целью настоящего исследования явилось изучение эпидемиологии и факторов риска ХОБЛ в экологических и климатических условиях Самары - крупного промышленного центра Среднего Поволжья.

\section{Материалы и методы}

Была сформирована случайная выборка взрослого населения Кировского и Красноглинского районов Самары, обслуживающегося в поликлинических отделениях ММУ "Медико-санитарная часть № 5" (Кировский район) и ММУ "Городская больница № 7" (Красноглинский район). Экологическую обстановку в индустриально развитом Кировском районе формируют такие крупные промышленные предприятия, как ОАО "Самарский металлургический завод", ОАО "Моторостроитель", Самарская и Безымянская ТЭЦ, ОАО "Авиакор". По сводным данным территориального управления Роспотребнадзора, среди вредных веществ, оказывающих наибольшее влияние на бронхолегочную систему, в Кировском районе преобладают сернистый ангидрид, оксиды углерода и азота, летучие органические смеси, аммиак, 
Таблица 1

Распространенность ХОБЛ среди мужчин и женщин

\begin{tabular}{|c|c|c|c|c|c|c|}
\hline \multirow{2}{*}{$\begin{array}{l}\text { Возрастная } \\
\text { группа, лет }\end{array}$} & \multicolumn{2}{|c|}{ Мужчины } & \multicolumn{2}{|c|}{ Женщины } & \multicolumn{2}{|c|}{ Общая выборка } \\
\hline & всего, $n$ & больные ХОБЛ, $n$ (\%) & всего, $n$ & больные ХОБЛ, $n$ (\%) & всего, $n$ & больные ХОБЛ, $n$ (\%) \\
\hline $30-39$ & 238 & $29(12,18)$ & 301 & $29(9,63)$ & 539 & $58(10,76)$ \\
\hline $40-49$ & 229 & $33(14,41)$ & 276 & $22\left(7,97^{\star}\right)$ & 505 & $55(10,89)$ \\
\hline $50-59$ & 248 & $53(21,37)$ & 325 & $38(11,69 * *)$ & 573 & $91(15,88)$ \\
\hline$\geq 60$ & 188 & $54(28,72)$ & 258 & $41\left(15,89^{* *}\right)$ & 446 & $95(14,49)$ \\
\hline Всего & 903 & $169(18,72)$ & 1160 & $130\left(11,21^{\star \star *}\right)$ & 2063 & $299(14,49)$ \\
\hline
\end{tabular}

Примечание: * $-p<0,05 ;{ }^{* *}-p<0,01 ;{ }^{* * *}-p<0,001$ по сравнению с обследованными мужчинами из соответствующих возрастных групп.

хлористый водород, сажа, фтористые соединения, формальдегид, фенол, ацетон, бензин. Их концентрация превышает допустимый уровень. Этот район города был отнесен к экологически неблагополучным, в отличие от Волжского склона и прилегающих к нему микрорайонов (Красноглинский район). В Красноглинском районе, кроме ОАО "СНТК им. Н.Д.Кузнецова" (конструкторское бюро), отсутствуют крупные промышленные предприятия и магистрали городского значения. Эта территория города хорошо аэрируется и озеленена в достаточной степени. Выбросы в атмосферу в Красноглинском районе характеризовались меньшим количеством вредных веществ и более низкой суммарной концентрацией, чем в Кировском районе. В основном преобладали летучие органические смеси, пары бензина, хлористый водород и сажа. При проведении клинико-эпидемиологического исследования этот участок города был отнесен к экологически благополучным.

На эпидемиологическом этапе прошли обследование 2063 человека (903 мужчины и 1160 женщин) в 4 возрастных группах: 30-39 лет, 40-49 лет, 50-59 лет, $\geq 60$ лет (планировалось обследовать 2800 человек - по 350 человек в каждой возрастной группе среди мужчин и женщин, ответ на исследование составил 73,68 \%), т. е. анализ эпидемиологических особенностей ХОБЛ проводился среди людей молодого, зрелого и старшего возраста. Чтобы выявить истинную распространенность ХОБЛ, на основании анкеты Европейского сообщества угля и стали (1993) был разработан стандартизированный вопросник, учитывающий особенности как эпидемиологического, так и социологического исследования [7, 8]. Все пациенты с респираторными жалобами прошли углубленное клинико-функциональное обследование с обязательным проведением компьютерной пневмотахографии.

Диагноз ХОБЛ устанавливался на основании критериев программы "Глобальная стратегия диагностики, лечения и профилактики ХОБЛ" [4] и клинических рекомендаций по пульмонологии, разработанных и рекомендованных Российским респираторным обществом $[2,3,6,9]$.

\section{Результаты и обсуждение}

Результаты исследования показали достаточно высокую распространенность ХОБЛ среди населения Самары. В общей выборке заболевание было выяв- лено у 14,49\% из 2063 обследованных (в группе 30-39 лет - у 10,76 \%, 40-49 лет - у 10,89\%, 50-59 лет - у 15,88 \%, $\geq 60$ лет - у 21,30\%). Диагноз ХОБЛ был установлен у 18,72\% из всех 903 обследованных мужчин и у 11,21\% из 1160 женщин $(p<0,001)$. Среди мужчин 30-39 лет распространенность ХОБЛ составила $12,18 \%, 40-49$ лет - 14,41 \%, 50-59 лет $21,37 \%(p>0,05), \geq 60$ лет $-28,72 \%(p>0,05)$. У женщин в возрастной группе 30-39 лет ХОБЛ была диагностирована в 9,63\% случаев $(p<0,05), 40-49$ лет - в 7,97\% $(p>0,05), 50-59$ лет - в 11,69\%, $\geq 60$ лет - в 15, $89 \%$ (табл. 1).

При анализе респираторного анамнеза выявлено, что среди обследованных с установленным в ходе эпидемиологического исследования диагнозом ХОБЛ 31 человек (2 человека в возрастной группе 40-49 лет, 8 человек в возрастной группе 50-59 лет, 21 человек в возрастной группе $\geq 60$ лет) состоял на диспансерном учете по поводу заболевания дыхательной системы (хронического обструктивного бронхита, ХОБЛ), течение которого было средне-тяжелым или тяжелым. Лица с ранее определенным диагнозом составляют 1,5 \% от общей выборки обследованных (10,37\% от общего числа лиц с диагнозом ХОБЛ, установленным в ходе эпидемиологического исследования). Это свидетельствует о значительной гиподиагностике ХОБЛ на амбулаторном этапе: регистрируются, как правило, только случаи со средне-тяжелым и тяжелым течением ХОБЛ.

Среди курящих мужчин ХОБЛ выявлена в 32,04\% случаев, среди некурящих - в 6,22 \% (относительный риск $(\mathrm{OP})=5,1511$; этиологическая фракция $(Э Ф)=80,59 \%)$. У обследованных женщин ХОБЛ обнаружена в 22,83 \% случаев среди курящих и в $9,78 \%$ - среди некурящих (ОР = 2,3344; ЭФ = $57,16 \%)$. В табл. 2 и 3 представлена зависимость распространенности ХОБЛ от табакокурения в различных возрастных группах.

Значима и зависимость распространенности ХОБЛ от интенсивности табакокурения. Среди мужчин, выкуривающих до 10 сигарет в сутки, доля больных ХОБЛ составляет 22,43 \%. Мужчины, выкуривающие 10-20 сигарет в сутки, болеют ХОБЛ значительно чаще $(34,35$ \%). Среди мужчин, выкуривающих > 20 сигарет в сутки, ХОБЛ встречается еще чаще - в 37,0 \% случаев. Среди женщин, выкуривающих в сутки до 10 сигарет, ХОБЛ была выявлена в 18,18\% случаев, среди выкуривающих 10-20 сигарет - в $24,0 \%$. 
Таблица 2

Распространенность ХОБЛ среди курящих и некурящих мужиин

\begin{tabular}{|c|c|c|c|c|c|}
\hline \multirow[t]{2}{*}{ Возрастная группа, лет } & \multirow[t]{2}{*}{ Bcero } & \multicolumn{2}{|c|}{ Некурящие } & \multicolumn{2}{|c|}{ Курящие } \\
\hline & & всего, $n$ & больные ХОБЛ, n (\%) & всего, $n$ & больные ХОБЛ, n (\%) \\
\hline $30-39$ & 238 & 90 & $8(2,22)$ & 148 & $27\left(18,24^{*}\right)$ \\
\hline $40-49$ & 229 & 109 & $4(3,67)$ & 120 & $29\left(24,17^{*}\right)$ \\
\hline $50-59$ & 248 & 146 & $9(6,16)$ & 102 & $44\left(43,14^{*}\right)$ \\
\hline$\geq 60$ & 188 & 121 & $14(11,57)$ & 67 & $40\left(59,70^{*}\right)$ \\
\hline Всего & 903 & 466 & $29(6,22)$ & 437 & $140\left(32,04^{\star}\right)$ \\
\hline
\end{tabular}

Примечание: * - $p<0,05$ в сравнении с некурящими.

Таблица 3

Распространенность ХОБЛ среди курящих и некурящих женщин

\begin{tabular}{|c|c|c|c|c|c|}
\hline \multirow[t]{2}{*}{ Возрастная группа, лет } & \multirow[t]{2}{*}{ Bcero } & \multicolumn{2}{|c|}{ Некурящие } & \multicolumn{2}{|c|}{ Курящие } \\
\hline & & всего, $n$ & больные ХОБЛ, $n$ (\%) & всего, $n$ & больные ХОБЛ, $n$ (\%) \\
\hline $30-39$ & 301 & 232 & $16(6,89)$ & 69 & $13\left(18,84^{\star \star}\right)$ \\
\hline $40-49$ & 276 & 251 & $17(6,77)$ & 25 & $5\left(20,00^{*}\right)$ \\
\hline 50-59 & 325 & 305 & $32(10,49)$ & 20 & $6\left(30,00^{*}\right)$ \\
\hline$\geq 60$ & 258 & 245 & $36(14,69)$ & 13 & $5(38,46)$ \\
\hline Всего & 1160 & 1033 & $101(9,78)$ & 127 & $29\left(22,83^{\star}\right)$ \\
\hline
\end{tabular}

Примечание: * - $p<0,05 ;{ }^{* *}-p<0,01$ в сравнении с некурящими.

Установлено, что среди мужчин, подверженных частым острыми респираторными заболеваниями (ОР3), ОР развития ХОБЛ в 1,99 раза выше, а среди женщин - в 2,02 раза выше, чем среди редко болеющих. Так, у мужчин 30-39 лет ХОБЛ была диагностирована в $10,10 \%$ и $22,50 \%$ случаев среди редко и часто болеющих ОР3 соответственно, 40-49 лет в $12,10 \%$ и $25,64 \%, 50-59$ лет - в $17,95 \%$ и $33,96 \%$, $\geq 60$ лет - в $25,00 \%$ и 40,91\% (табл. 4). В общей мужской популяции ХОБЛ была диагностирована у 114 человек из $727(15,68 \%)$ редко болеющих ОР3 и у 55 человек из $176(31,25 \%)$ часто болеющих ОР3 $(p<0,01 ;$ OP $=1,9929 ;$ ЭФ $=49,83 \%)$.
Среди женщин 30-39 лет ХОБЛ была выявлена в $7,79 \%$ и $15,71 \%$ случаев среди редко и часто болеющих ОР3 соответственно, 40-49 лет - в 6,70\% и $13,46 \%, 50-59$ лет - в 9,63\% и $21,82 \%, \geq 60$ лет в $13,53 \%$ и $25,49 \%$ (табл. 5). В общей популяции обследованных женщин при анализе эпидемиологической характеристики ХОБЛ по признаку редко и часто болеющих, среди первых заболевание диагностируется у 87 женщин из $932(9,33 \%)$ и среди вторых - у 43 из $228(18,86 \%)(\mathrm{OP}=2,0214 ; Э Ф=50,53 \% ; p<0,01)$.

ХОБЛ была диагностирована у $13,33 \%$ мужчин, живущих в экологически благополучном Красноглинском районе, и у 23,72 \% мужчин, проживающих

Таблица 4

Зависимость распространенность ХОБЛ среди мужчин от частоты ОРЗ

\begin{tabular}{l|c|c|c|c|} 
Возрастная группа, лет & \multicolumn{2}{|c|}{ Редко болеющие } & \multicolumn{2}{c}{ Часто болеющие } \\
\cline { 2 - 4 } & Всего, $n$ & Больные ХОБл, $n(\%)$ & Всего, $n$ & 40 \\
$30-39$ & 198 & $20(10,10)$ & 39 & $10\left(25,64^{*}\right)$ \\
$40-49$ & 190 & $23(12,10)$ & 53 & $18\left(33,96^{*}\right)$ \\
$50-59$ & 195 & $35(17,95)$ & 44 & $18(40,91)$ \\
$\geq 60$ & 144 & $36(25,00)$ & 176 & $55\left(31,25^{* *}\right)$
\end{tabular}

Примечание: * - $><0,05 ;{ }^{* *}-p<0,001$ в сравнении с группой редко болеющих.

Таблица 5

Зависимость распространенности ХОБЛ среди женщин от частоты ОРЗ

\begin{tabular}{|c|c|c|c|c|}
\hline \multirow[t]{2}{*}{ Возрастная группа, лет } & \multicolumn{2}{|c|}{ Редко болеющие } & \multicolumn{2}{|c|}{ Часто болеющие } \\
\hline & Bcero, $n$ & Больные ХОБЛ, $n$ (\%) & Bcero, $n$ & Больные ХОБЛ, $n$ (\%) \\
\hline $30-39$ & 231 & $18(7,79)$ & 70 & $11(15,71)$ \\
\hline $40-49$ & 224 & $15(6,70)$ & 52 & $7(13,46)$ \\
\hline $50-59$ & 270 & $26(9,63)$ & 55 & $12\left(21,82^{\star}\right)$ \\
\hline$\geq 60$ & 207 & $28(13,53)$ & 51 & $13(25,49)$ \\
\hline Всего & 932 & $87(9,33)$ & 228 & $43\left(18,86^{\star *}\right)$ \\
\hline
\end{tabular}

Примечание: * $-p<0,05 ;{ }^{* *}-p<0,001$ в сравнении с группой редко болеющих. 
в экологически неблагополучном Кировском районе $(p<0,05)$. Таким образом, относительный риск развития ХОБЛ среди мужчин, проживающих в экологически неблагополучном районе, в 1,78 раза выше $(\mathrm{OP}=1,7794 ;$ ЭФ = 43,80\%). У женщин ХОБЛ выявлена в 9,04\% случаев в экологически благополучном Красноглинском районе и в 13,11 \% в Кировском районе $(p<0,05)$. Таким образом, относительный риск развития ХОБЛ у женщин, проживающих в экологически неблагоприятном районе, в 1,45 раза выше $(\mathrm{OP}=1,4502 ; \ni \Phi=31,10 \%)$. В табл. 6 и 7 представлена зависимость распространенности ХОБЛ от экологических условий в различных возрастных группах среди мужчин и женщин.

Несомненно, повышенное содержание в атмосферном воздухе различных химических аэрозолей: сернистого газа, окислов азота и других вредных веществ вызывает транзиторное повышение реактивности бронхов, бронхоконстрикцию, и поэтому проживание на загрязненных территориях можно расценивать как фактор риска развития заболеваний органов дыхания, в т. ч. ХОБЛ.

Выявлена зависимость распространенности ХОБЛ от образования человека, которое предопределяет уровень санитарной культуры и распространенность в популяции различных вредных привычек, провоцирующих развитие респираторных симптомов, в т. ч. табакокурения. ХОБЛ встречается среди мужчин с незаконченным средним образованием в 31,16 \% случаев, среди мужчин со средним и средне-специальным образованием - в 18,59 \%, среди мужчин с высшим образованием - в 10,81 \% случаев. Среди женщин с незаконченным средним образованием ХОБЛ выявлена в 23,92 \% случаев, со средним образованием - в 6,02\%, с высшим образованием - в 3,26\% случаев.
ХОБЛ диагностирована в $31,93 \%$ случаев у мужчин с заболеваниями легких в семейном анамнезе и в $16,71 \%$ - у мужчин без семейного анамнеза $(p<0,05 ; \mathrm{OP}=1,9108 ; Э Ф=47,67 \%)$. У женщин с патологией легких в семейном анамнезе ХОБЛ обнаружена в $22,13 \%$ случаев и в $8,30 \%-$ у женщин без отягощенной наследственности по заболеваниям легких $(p<0,05 ;(\mathrm{OP}=2,6662 ;$ ЭФ $=62,50 \%)$.

Эти данные подтверждаются мнением акад. РАМН проф. А.Г.Чучалина и других исследователей $[2,5]$ о том, что любые этиологические факторы риска ХОБЛ (внешние аэрозоли, табакокурение) оказывают свое действие на фоне имеющейся наследственной предрасположенности, проявляющейся в большей чувствительности рецепторов слизистой оболочки бронхов к аэрополлютантам, и снижения местной иммунологической реактивности, способствующего бактериальному инфицированию и возникновению инфекционнозависимых обострений ХОБЛ.

Среди мужчин ОР развития ХОБЛ выше в 2,91 раза у лиц с хроническими заболеваниями верхних дыхательных путей (хронический тонзиллит, ринит), чем у не имеющих их (распространенность ХОБЛ составила $35,43 \%$ и $12,17 \%$ соответственно; ОР = 2,9113; ЭФ $=65,65 \%)$. У женщин ОР возникновения ХОБЛ в 2,72 раза выше среди лиц с хроническими заболеваниями верхних дыхательных путей $(19,06 \%$ случаев, по сравнению с 7,01\% у женщин без данной патологии; ОР =2,7189; ЭФ = 63,22 \%). Повышенная распространенность ХОБЛ в этом случае, очевидно, связана с тем, что при хроническом тонзиллите, который является очагом постоянной инфекции, бронхиальное дерево становится более уязвимым, а при рините происходит нарушение обезвреживания микроорганизмов и элиминации пылевых и химических аэрозолей из верхних дыхательных путей.

Таблица 6

Зависимость распространенности ХОБЛ среди мужчин от экологических условий

\begin{tabular}{|c|c|c|c|c|}
\hline \multirow[t]{2}{*}{ Возрастная группа, лет } & \multicolumn{2}{|c|}{ Экологически неблагополучный район } & \multicolumn{2}{|c|}{ Экологически благополучный район } \\
\hline & всего, $n$ & больные ХОБЛ, $n$ (\%) & всего, $n$ & больные ХОБЛ, $n$ (\%) \\
\hline 30-39 & 121 & $19(15,70)$ & 117 & $10(8,55)$ \\
\hline $40-49$ & 120 & $21(17,50)$ & 109 & $12(11,01)$ \\
\hline $50-59$ & 131 & $37(28,24)$ & 117 & $16\left(13,68^{*}\right)$ \\
\hline$\geq 60$ & 96 & $34(35,42)$ & 92 & $20(21,74)$ \\
\hline Bcero & 468 & $111(23,72)$ & 435 & $58\left(13,33^{* *}\right)$ \\
\hline
\end{tabular}

Примечание: * - p<0,01; ** - p<0,001 в сравнении с проживающими в экологически неблагоприятном районе.

Таблица 7 Зависимость распространенности ХОБЛ среди женщин от экологических условий

\begin{tabular}{|c|c|c|c|c|}
\hline \multirow[t]{2}{*}{ Возрастная группа, лет } & \multicolumn{2}{|c|}{ Экологически неблагополучный район } & \multicolumn{2}{|c|}{ Экологически благополучный район } \\
\hline & всего, $n$ & больные ХОБЛ, $n$ (\%) & всего, $n$ & больные ХОБЛ, $n$ (\%) \\
\hline $30-39$ & 163 & $19(11,66)$ & 138 & $10(3,25)$ \\
\hline 40-49 & 140 & $14(10,00)$ & 136 & $8(5,88)$ \\
\hline $50-59$ & 176 & $22(12,50)$ & 149 & $16(10,74)$ \\
\hline$\geq 60$ & 139 & $26(18,71)$ & 119 & $15(12,61)$ \\
\hline Всего & 618 & $81(13,11)$ & 542 & $49\left(9,04^{*}\right)$ \\
\hline
\end{tabular}

Примечание: * - p<0,05 в сравнении с проживающими в экологически неблагоприятном районе. 
В общей выборке мужчин ХОБЛ встречалась в 1,32 раза чаще среди злоупотребляющих алкоголем $(\mathrm{OP}=1,3178 ;$ ЭФ $=24,12 \%)$, чем при умеренном употреблении алкоголя (распространенность заболевания $-23,26 \%$ и $17,65 \%$ соответственно). Аналогичная ситуация наблюдается и в женской популяции: случаи ХОБЛ встречаются в 1,19 раза чаще у злоупотребляющих алкоголем - в 13,21 \% (ОР = 1,1998; ЭФ $=16,65 \%)$, чем среди употребляющих его в умеренном количестве $(11,01 \%)$.

\section{Заключение}

Таким образом, впервые были изучены распространенность и факторы риска ХОБЛ в крупном промышленном центре Среднего Поволжья - Самаре. На основе методов клинической эпидемиологии и доказательной медицины определен ОР развития ХОБЛ среди лиц, экспонированных к воздействию различных факторов риска.

Результаты проведенного исследования согласуются с данными, полученными в других крупных промышленных центрах Российской Федерации. Так, истинная распространенность ХОБЛ составила $14,49 \%$ случаев среди всех обследованных и была диагностирована у $18,71 \%$ мужчин и $11,21 \%$ женщин.

Ведущими факторами риска являются пожилой возраст, мужской пол, табакокурение, перенесенные респираторные инфекции, хронические заболевания верхних дыхательных путей, экологическое неблагополучие в районе проживания, отсутствие семьи, низкий образовательный уровень, злоупотребление алкоголем.

\section{Литература}

1. Величковский Б.Т. О путях "сбережения народа" и роли болезней органов дыхания в решении этой проблемы. Пульмонология 2007; 3: 5-9.

2. Чучалин А.Г. Белая книга. Пульмонология. М.: Медицина; 2004. 7-34.

3. Шмелев Е.И. Хроническая обструктивная болезнь легких и сопутствующие заболевания. Пульмонология 2007; 2: 5-10.

4. Global initiative for chronic obstructive lung disease. National Institutes of Health. www.goldcopd.com.

5. Жестков А.В., Бабанов С.А., Косарев В.В. Эволюция представлений о хронической обструктивной болезни легких. Самар. мед. журн. 2008; 2: 3-6.

6. Лещенко И.В., Эсаулова Н.А. Основные положения международных клинических рекомендаций по диагностике и лечению хронической обструктивной болезни легких. Пульмонология 2005; 3: 101-109.

7. Бабанов С.А. Распространенность табакокурения среди городского населения Самары и факторы, ее определяющие. Тер. арх. 2008; 1: 69-73.

8. Ядов В.А. Социологическое исследование: методология, программа, методы. М.; 1987. 23-29.

9. Хроническая обструктивная болезнь легких. Клинические рекомендации. М.: Атмосфера; 2007.

\section{Информация об авторах}

Жестков Александр Викторович - д. м. н., проф., зав. кафедрой общей и клинической микробиологии, иммунологии и аллергологии Самарского государственного медицинского университета, главный аллерголог-иммунолог Минздравсоцразвития Самарской обл.; тел.: (846) 260-33-61; e-mail: zhestkov@rambler.ru

Косарев Владислав Васильевич - д. м. н., проф., зав. кафедрой профессиональных болезней и клинической фармакологии Самарского государственного медицинского университета, заслуженный деятель науки РФ, главный профпатолог Минздравсоцразвития Самарской обл.; тел.: (846) 241-92-87; e-mail: info@samsmu.ru

Бабанов Сергей Анатольевич - д. м. н., ассистент кафедры профессиональных болезней и клинической фармакологии Самарского государственного медицинского университета; тел.: (846) 241-92-86; e-mail: s.a.babanov@mail.ru 